\section{H1N1 Influenza: Contact Investigation Burden because of Failure to Institute Influenza Precautions in Patients with Negative Rapid Influenza Diagnostic Test Results}

Winthrop-University Hospital is a university-affiliated, 600bed tertiary care teaching hospital in the New York epicenter of the H1N1 influenza pandemic. From April through June 2009, Winthrop-University Hospital and emergency departments (EDs) at other area hospitals were inundated with patients with influenza-like illness who visited the hospital for H1N1 influenza screening. ${ }^{1}$ The $\mathrm{ED}$ at Winthrop-University Hospital uses the rapid influenza A test (QuickVue A/ B) to screen ambulatory and admitted patients with influenza-like illness. The vast numbers of patients presenting to the ED for H1N1 influenza testing severely taxed the testing capability. In patients admitted to the ED with probable $\mathrm{H} 1 \mathrm{~N} 1$ influenza, implementation of influenza precautions was based on the rapid influenza A test results. Unfortunately, the rapid influenza A test is associated with $30 \%$ false-negative results. As predicted, many patients admitted to Winthrop-University Hospital with presumptive H1N1 influenza were not placed on appropriate precautions in the ED. Because of $30 \%$ falsenegative results with the rapid influenza $A$ test, oropharyngeal specimens were obtained for respiratory fluorescent antibody viral testing. The respiratory fluorescent antibody viral panel detects influenza A and B viruses, metapneumoviruses, respiratory syncytial virus, parainfluenza viruses, and adenoviruses. Specimens were obtained from admitted patients with presumed $\mathrm{H} 1 \mathrm{~N} 1$ influenza for rapid influenza A testing, respiratory fluorescent antibody viral panel testing, and reversetranscription polymerase chain reaction (RT-PCR) for detection of $\mathrm{H} 1 \mathrm{~N} 1$ influenza; rapid influenza $\mathrm{A}$ and respiratory fluorescent antibody viral test results were discordant. ${ }^{2,3}$ The definitive laboratory diagnosis of $\mathrm{H} 1 \mathrm{~N} 1$ influenza was not often possible, because the health department was inundated with huge numbers of requests and refused most specimens for RT-PCR testing; in addition, when the test was performed, results were not reported until much later.

Winthrop-University Hospital and other hospitals had difficulties deciding which patients with influenza-like illness had probable H1N1 influenza (ie, which patients should be placed on influenza precautions and receive treatment with oseltamivir). Patients admitted to the hospital who had positive rapid influenza $A$ test results in the ED were immediately placed on appropriate influenza precautions and given oseltamivir. Patients admitted to the hospital who had negative rapid influenza A test results posed a major infection control problem. Respiratory fluorescent antibody viral panel results were not rapidly available, which limited the usefulness of the test in determining which patients were unlikely to have HIN1 influenza and could have influenza precautions discontinued. Because specimens for RT-PCR for a definitive diagnosis of H1N1 influenza were refused or results were not rapidly reported, determination of which patients should be placed on influenza precautions, as well as contact investigations, were needlessly complicated. Definitive results of H1N1 influenza RT-PCR were usually reported after the results were clinically or epidemiologically relevant.

Because of the diagnostic dilemmas and discordant laboratory results of influenza $A$ tests (ie, rapid influenza $A$ or respiratory fluorescent antibody viral panel tests), we applied clinical criteria to admitted adult patients with negative influenza A test results. ${ }^{4,5}$ Unfortunately, patients admitted to the hospital with probable H1N1 influenza were not often placed on influenza precautions or treated with oseltamivir, because results of their rapid tests for influenza A were negative.

The patients with negative results of the rapid influenza $A$ test who had probable H1N1 influenza placed an enormous burden on the Infection Control Section and the Employee Health Service. For patients admitted to the hospital with presumed H1N1 influenza, infection control workers had to perform contact investigations of exposed patients and the Employee Health Service had to performed contact investigations of healthcare workers.

Problems with initiation of influenza precautions on the basis of negative rapid influenza $A$ test results were overwhelming from April through May. Starting in June 2009, the Infectious Diseases Division used clinical and laboratory criteria to presumptively diagnosis probable $\mathrm{H} 1 \mathrm{~N} 1$ influenza and to place patients on appropriate influenza precautions. The most useful clinical marker in patients with influenzalike illness and presumed $\mathrm{H} 1 \mathrm{~N} 1$ influenza was otherwise unexplained relative lymphopenia. Relative lymphopenia (ie, less than $21 \%$ lymphocytes) was present in all adult patients with a clinical presentation suggestive of $\mathrm{H} 1 \mathrm{~N} 1$ influenza (ie, myalgias and/or shortness of breath). In patients who had relative lymphopenia due to other causes, an elevated creatine phosphokinase level, thrombocytopenia, or mildly increased serum transaminase levels were other markers of HiNl influenza. ${ }^{2,3,-8}$ The Infectious Diseases Division and Infection Control Section reviewed the records of every patient admitted to the ED with presumed H1N1 influenza to determine whether precautions and/or oseltamivir treatment should be continued or discontinued.

Employee Health Service resources were taxed to the limit because of extensive contact investigations of healthcare workers in contact with patients with potential H1N1 influenza to determine which healthcare workers should be fur- 
TABLE Infection Control and Employee Health Service Contact Investigations for Patients Admitted to the Emergency Department at Winthrop-University Hospital with Probable H1N1 Influenza Who Are Not Placed on Influenza Precautions (April-May 2009)

\begin{tabular}{|c|c|c|c|c|c|c|}
\hline Patient & Sex & $\begin{array}{l}\text { Age, } \\
\text { years }\end{array}$ & $\begin{array}{c}\text { Rapid } \\
\text { influenza A } \\
\text { test result }\end{array}$ & $\begin{array}{l}\text { Time from } \\
\text { admission to } \\
\text { implementation } \\
\text { of influenza } \\
\text { precautions, days }\end{array}$ & $\begin{array}{l}\text { No. of } \\
\text { healthcare worker } \\
\text { contact investigations }\end{array}$ & $\begin{array}{c}\text { No. of exposed } \\
\text { healthcare workers/no. } \\
\text { who received } \\
\text { oseltamivir } \\
\text { prophylaxis }\end{array}$ \\
\hline 1 & $\mathrm{~F}$ & 4 & - & 3 & 67 & $50 / 50$ \\
\hline 2 & M & 42 & $+^{a}$ & 1 & 11 & $3 / 3$ \\
\hline 3 & $\mathrm{~F}$ & 15 & $t^{a}$ & 2 & 29 & $14 / 6$ \\
\hline 4 & $\mathrm{~F}$ & 70 & $t^{a}$ & 1 & 8 & $8 / 5$ \\
\hline 5 & M & 1 & - & 1 & 15 & $6 / 6$ \\
\hline 6 & $\mathrm{~F}$ & 39 & - & 3 & 10 & $7 / 6$ \\
\hline 7 & $\mathrm{~F}$ & 45 & - & 4 & 25 & $0 / 0$ \\
\hline 8 & $M$ & 71 & - & 2 & 20 & $8 / 8$ \\
\hline 9 & $\mathrm{~F}$ & 16 & - & NA & 2 & $4 / 4$ \\
\hline 10 & M & 3 & - & NA & 6 & $1 / 1$ \\
\hline $11^{\mathrm{b}}$ & $\mathrm{F}$ & 54 & - & NA & 41 & $3 / 1$ \\
\hline $12^{b}$ & M & 23 & - & NA & 47 & $7 / 7$ \\
\hline $13^{\mathrm{b}}$ & $\mathrm{F}$ & 27 & - & NA & 2 & $2 / 2$ \\
\hline $14^{\mathrm{b}}$ & $\mathrm{M}$ & 28 & - & NA & 15 & $4 / 3$ \\
\hline
\end{tabular}

NOTE. A total of 298 contact investigations were performed, 117 health care workers were exposed to HiNl influenza virus, and 102 health care workers received prophylaxis. NA, not applicable

- Positive rapid influenza $A$ test result but not placed on influenza precautions.

${ }^{b}$ Health care workers who came to work sick with probable H1N1 influenza and exposed patients and/or staff in a clinic.

loughed and which should be allowed to work while receiving oseltamivir prophylaxis. From April through June, 14 patients and healthcare workers had presumed H1N1 influenza, requiring 298 contact investigations. The Employee Health Service determined that 117 potential exposures were related to the index cases. The time from hospital admission to placement of patients on precautions for presumed HINl influenza who had negative rapid influenza $A$ test results varied from 1 to 4 days. Of the healthcare workers with potential HIN1 influenza, 102 were considered to be close contacts and 90 were offered oseltamivir prophylaxis and/or were furloughed. (Table)

By June, the number of patients with presumed H1N1 influenza who had not been placed on appropriate precautions after hospital admission decreased because of several factors. One factor was the recognition that negative screening test results (ie, rapid influenza $A$ and/or respiratory fluorescent antibody viral panel tests) did not rule out H1N1 influenza. Second, clinical criteria of the Infection Diseases Division was used for diagnosis of presumptive H1N1 influenza (ie, otherwise unexplained relative lymphopenia, elevated creatine phosphokinase level, thrombocytopenia, and elevated serum transaminase levels, combined with a history of signs and symptoms, including fever and/or chills, dry cough, shortness of breath, and myalgias) and for identifying cases and placing patients on influenza precautions. Third, the decision to institute influenza precautions and/or oseltamivir treatment was determined by the Infection Control Section and Infectious Diseases Department and was no longer based on neg- ative rapid influenza $\mathrm{A}$ test results. Although this approach was not perfect, it greatly decreased the burden of contact investigations of exposed healthcare workers and patients. Key clinical and laboratory tests that proved to be useful in identifying patients with probable H1N1 influenza were also useful in identifying patients with influenza-like illness who had a low probability of having HIN1 influenza and did not require influenza precautions. ${ }^{2,3}$

\section{ACKNOWLEDGMENTS}

Potential conflicts of interest. All authors report no conflicts of interest relevant to this article.

Burke A. Cunha, MD;

Valsamma Thekkel, RN, MSC, CIC;

Carol Cohan, RN, MHA

From the Infectious Disease Division, Infection Control Section, and Employee Health Service, Winthrop-University Hospital, Mineola, and State University of New York School of Medicine, Stony Brook, New York (all authors).

Address reprint requests to Burke A. Cunha, MD, Winthrop-University Hospital, Mineola, NY 11501.

Infect Control Hosp Epidemiol 2010; 31:102-104

(C) 2009 by The Society for Healthcare Epidemiology of America. All rights reserved. 0899-823X/2010/3101-0019\$15.00. DOI: $10.1086 / 649762$

\section{REFERENCES}

1. Centers for Disease Control and Prevention. Outbreak of swine-origin 
influenza A (H1N1) virus infection-Mexico, March-April 2009. MMWR Morb Mortal Wkly Rep 2009; 58:467-470.

2. Cunha BA, Pherez FM, Klein NC, et al. Swine influenza (H1N1) screening tests: problems \& inconsistencies. Eur J Clin Microbiol Infect Dis 2009 (in press).

3. Cunha BA, Pherez FM, Strollo S. Swine influenza (H1N1): diagnostic dilemmas early in the pandemic. Scand J Infect Dis 2009 (in press).

4. Cunha BA, McDermott BP, Mohan SS. The diagnostic and prognostic significance of relative lymphopenia in adult patients with influenza $A$. Am J Med 2005; 118:1307-1309.

5. Cunha BA, Pherez FM, Schoch P. The diagnostic importance of relative lymphopenia as a marker of swine influenza $(\mathrm{H} 1 \mathrm{~N} 1)$ in adults. Clin Infect Dis 2009; 49:1454-1456.

6. Criswell S, Couch BS RB, Greenberg SB, et al. The lymphocyte response to influenza in humans. Am Rev Respir Dis 1979; 120:700-704.

7. Van Campen H, Easterday BC, Hinshaw VS. Destruction of lymphocytes by a virulent avian influenza A virus. J Gen Virol 1989; 70:467-472.

8. Tumpey TM, Lu X, Morken T, et al. Depletion of lymphocytes and diminished cytokine production in mice infected with a highly virulent influenza A (H1N1) virus isolated from humans. J Virol 2000; 74:6105-6116.

\section{Legionnaires Disease-Reordered}

To the Editor-Legionnaires disease can be classified into 3 exposure categories depending on the assumed environment of the exposure that led to infection: community-acquired Legionnaires disease, travel-associated Legionnaires disease, and nosocomially acquired Legionnaires disease. The disease frequency of Legionnaires disease by category is commonly presented as a proportion of cases of Legionnaires disease classified according to type of exposure among all cases for which exposure category is reported. In European countries, most cases of Legionnaires disease during the period from 2004 through 2006 were community acquired (66\%); few- er were travel associated $(27 \%)$ or nosocomially acquired $(7 \%))^{1,2}$ However, this representation does not take into account the number of person-days at risk within the exposure types. The number of cases divided by the number of persondays at risk is the incidence and should give another perspective on the likelihood of individuals to acquire Legionnaires disease when exposed within these categories.

We examined German data on cases of Legionnaires disease that were reported to the Robert Koch-Institute during the period from 2004 through 2006. These were classified in the following 4 categories: community-acquired Legionnaires disease, travel-associated Legionnaires disease, nosocomially acquired Legionnaires disease, and Legionnaires disease acquired in a nursing home. We obtained data on person-days at risk from the Federal Statistical Office, Wiesbaden, Germany.-5 To determine the number of days that the population was hospitalized or spent in nursing homes, we used occupancy data (Table 1). Travel data were received in the form of number of nights that adults spent away from home for private or occupational purposes. ${ }^{6}$ Private travel days were extrapolated to the entire population according to the proportion of adults in the total population (travel days among adults divided by the proportion of adults among the total population) (Table 1). To obtain the number of days spent in the community, we subtracted the sum of the number of travel days, the number of days hospitalized, and the number of days spent in nursing homes from the total number of days lived by the German population (calculated as the mean of the total German population during 2004-2006 × 3 years $\times 365.25$ days per year).

During the period from 2004 through 2006, 942 cases of Legionnaires disease with known exposure category were reported in Germany: $102(11 \%)$ cases of nosocomially acquired Legionnaires disease, $23(2 \%)$ cases of Legionnaires

TABLE 1. Incidence, Incidence Rate Ratio, Mortality Rate, and Mortality Rate Ratio of Hospital-Acquired; Nursing Home-Acquired, Travel-Associated, and Community-Acquired Cases of Legionnaires Disease in Germany, 2004-2006

\begin{tabular}{|c|c|c|c|c|c|c|c|}
\hline Legionnaires disease exposure type & $\begin{array}{l}\text { No. of } \\
\text { patients }\end{array}$ & $\begin{array}{l}\text { No. of } \\
\text { days of } \\
\text { exposure, } \\
\text { thousands }\end{array}$ & $\begin{array}{l}\text { Incidence } \\
\text { per } 1 \text { billion } \\
\text { person-days } \\
\text { of exposure }\end{array}$ & $\begin{array}{c}\text { Incidence rate } \\
\text { ratio }^{\mathrm{a}}\end{array}$ & $\begin{array}{c}\text { Case-fatality } \\
\text { ratio, } \\
\text { no. }(\%)\end{array}$ & $\begin{array}{l}\text { Mortality rate } \\
\text { per } 1 \text { billion } \\
\text { person-days } \\
\text { under exposure }\end{array}$ & $\begin{array}{l}\text { Mortality rate } \\
\text { ratio }^{\mathbf{b}}\end{array}$ \\
\hline Hospital acquired (nosocomially acquired) & 102 & $432,241^{c}$ & 236.0 & 36.5 & $13 / 100(13.0)$ & 30.1 & 54.5 \\
\hline Nursing home acquired & 23 & $829,119^{d}$ & 27.7 & 4.3 & $3 / 23(13.0)$ & 3.6 & 6.4 \\
\hline Total healthcare associated & 125 & $1,261,360$ & 99.1 & 15.3 & $16 / 123(13.0)$ & 12.7 & 22.9 \\
\hline Travel associated & 270 & $4,460,527^{\mathrm{e}}$ & 60.5 & 9.4 & $12 / 264(4.6)$ & 2.7 & 4.9 \\
\hline
\end{tabular}

" Calculated by using the incidence of community-acquired Legionnaires disease as the reference.

${ }^{b}$ Calculated by using the mortality rate of patients with community-acquired Legionnaires disease as the reference.

' No. of days hospitalized.

"No. of days spent in nursing homes, calculated as no. of nursing home beds, assuming $100 \%$ occupancy. The no. for 2005 was the only one available, so it was multiplied by 3 to cover the period from 2004 through 2006.

- Travel days is the sum of days spent on occupational travel $(296,000,000)$ and nights spent on private travel by the general population $(4,164,527,000$ $\left.\left[N_{0}\right]\right) . \mathrm{N}_{0}$ was calculated from the no. of nights spent on private travel in the population $>14$ years old $\left(N_{>14 \text { years }}=3,569,000,000\right)$ and the proportion of the population $<15$ years old $(14.3 \%)$ by means of the formula $N_{0}=N_{>14 \text { years }} /(1-0.143)$.

f To obtain the no. of days spent in the community, we subtracted the sum of the no. of travel days, the no. of days hospitalized, and the no. of days spent in nursing homes from the total no. of days lived by the German population (mean of total German population during 2004-2006 $\times 3$ years $\times 365.25$ days per year). 